\title{
Genotyping of a gene cluster for production of colibactin and in vitro genotoxicity analysis of Escherichia coli strains obtained from the Japan Collection of Microorganisms
}

\author{
Masanobu Kawanishi ${ }^{1 *}$, Chiaki Shimohara ${ }^{1}$, Yoshimitsu Oda ${ }^{1}$, Yuuta Hisatomi ${ }^{1}$, Yuta Tsunematsu ${ }^{2}$, Michio Sato ${ }^{2}$, \\ Yuichiro Hirayama ${ }^{2}$, Noriyuki Miyoshi ${ }^{3}$, Yuji Iwashita ${ }^{4}$, Yuko Yoshikawa ${ }^{3,5}$, Haruhiko Sugimura ${ }^{4}$, Michihiro Mutoh $^{6}$, \\ Hideki Ishikawa ${ }^{7}$, Keiji Wakabayashi ${ }^{3}$, Takashi Yagi and Kenji Watanabe ${ }^{2}$
}

\begin{abstract}
Introduction: Colibactin is a small genotoxic molecule produced by enteric bacteria, including certain Escherichia coli (E. coli) strains harbored in the human large intestine. This polyketide-peptide genotoxin is considered to contribute to the development of colorectal cancer. The colibactin-producing $\left(\mathrm{clb}^{+}\right)$microorganisms possess a 54kilobase genomic island (clb gene cluster). In the present study, to assess the distribution of the $\mathrm{clb}$ gene cluster, genotyping analysis was carried out among E. coli strains randomly chosen from the Japan Collection of Microorganisms, RIKEN BRC, Japan.
\end{abstract}

Findings: The analysis revealed that two of six strains possessed a $c l b$ gene cluster. These $\mathrm{clb}^{+}$strains JCM5263 and JCM5491 induced genotoxicity in in vitro micronucleus (MN) tests using rodent CHO AA8 cells. Since the induction level of MN by JCM5263 was high, a bacterial umu test was carried out with a cell extract of the strain, revealing that the extract had SOS-inducing potency in the umu tester bacterium.

Conclusion: These results support the observations that the $\mathrm{clb}$ gene cluster is widely distributed in nature and $\mathrm{Clb}^{+}$E. coli having genotoxic potencies is not rare among microorganisms.

Keywords: Colibactin, Genotyping, Genotoxicity

\section{Introduction}

Colibactin is a small genotoxic molecule produced by $E n-$ terobacteriaceae, including certain Escherichia coli (E. coli) strains harbored in the human gut, and is involved in the etiology of colorectal cancer. The colibactin-producing $\left(\mathrm{clb}^{+}\right)$microorganisms possess a 54-kilobase genomic island ( $c l b$ gene cluster) encoding polyketide synthases (PKSs), nonribosomal peptide synthetases (NRPSs), and PKS-NRPS hybrid megasynthetases [1]. Nougayrede et al. observed

\footnotetext{
* Correspondence: kawanisi@riast.osakafu-u.ac.jp

${ }^{1}$ Graduate School of Science and Radiation Research Center, Osaka

Prefecture University, 1-2 Gakuen-cho, Naka-ku, Sakai-shi, Osaka 599-8570,

Japan

Full list of author information is available at the end of the article
}

DNA double-strand breaks and interstrand cross-links in human cell lines and in animals infected with $\mathrm{clb}^{+}$E. coli strains, resulting in generation of gene mutations [1]. The $\mathrm{clb}^{+}$E. coli stimulates growth of colon tumors under conditions of host inflammation, and is found with increased frequency in inflammatory bowel disease, familial adenomatous polyposis, and colorectal cancer patients [2, $3]$. We previously reported that $E$. coli strains isolated from a Japanese colorectal cancer patient produced colibactin and showed genotoxicity in in vitro assays $[4,5]$. However, the chemical structure of the genotoxin, the molecular mechanism of its mutagenesis/carcinogenesis, and distribution of the $c l b$ gene cluster among microorganisms have not been fully clarified yet. 
Table 1 Summary of genotyping and genotoxicity analyses

\begin{tabular}{lll}
\hline Strain & clb Gene cluster & Genotoxicity (MN test) \\
\hline JCM1246 & - & - \\
JCM1649T & - & - \\
JCM5263 & + & + \\
JCM5491 & $+^{\text {a }}$ & + \\
JCM18426 & - & - \\
JCM20114 & - & - \\
Nissle 1917 & $+^{\text {b }}$ & + \\
\hline
\end{tabular}

${ }^{a}$ Genotyping data are also confirmed in ref. [4]

${ }^{b}$ Genomic data are also from ref. [1]

The present study aimed to assess the distribution of the $c l b$ gene cluster among $E$. coli strains randomly chosen from the Japan Collection of Microorganisms, with genotyping of the gene cluster. To evaluate the association between presence of the cluster and genotoxicity, we examined the genotoxicity/clastogenicity of these E. coli strains in rodent cells using the in vitro micronucleus $(\mathrm{MN})$ test. Using the $u m u$ test, DNA damage in a bacterial tester strain treated with crude extracts of the $E$. coli was also evaluated.

\section{Materials and methods}

\section{E. coli strains and genotyping}

Six E. coli strains (Escherichia coli (Migula 1895) Castellani and Chalmers 1919) were randomly chosen and purchased from the Japan Collection of Microorganisms at the microbe division of the RIKEN BioResource Research Center (Tsukuba, Japan), which is participating in the National BioResource Project of the MEXT, Japan. E. coli Nissle 1917 strain was obtained from Mutaflor, Ardeypharm, GmbH. (Herdecke, Germany), and used as a $\mathrm{clb}^{+}$strain [1]. The host tester strain E. coli ZA227 used in the umu test was kindly supplied by Dr. Mie Watanabe-Akanuma (Institute of Environmental Toxicology, Tokyo, Japan). PCR analysis and electrophoresis for genotyping of the $c \mathrm{lb}^{+}$gene cluster was carried out with the oligonucleotide primers, as previously reported [4]. For genome analysis with next-generation sequencing, the $E$. coli genomic DNA was purified with MonoFas DNA Purification Kit V (GL Sciences In., Tokyo, Japan). Library construction and pairedend sequencing were carried out using the Miseq (Illumina Inc., San Diego, CA, U.S.A) with the Miseq reagent kits v2 (300 cycles). The raw sequence data were mapped by the HISAT2 program (ver. 2.1.0, Johns Hopkins University, Baltimore, MD, U.S.A) to the genome of Nissle1917 (GCA_000714595.1) as a reference sequence. The mapped files were converted to bam files by using SAMtools (ver1.9, http://www. htslib.org), and the read coverages were generated by StringTie (ver1.3.5, Johns Hopkins University) and the heatmap was constructed using the CIMminer program (National Cancer Institute, Bethesda, MD. U.S.A).

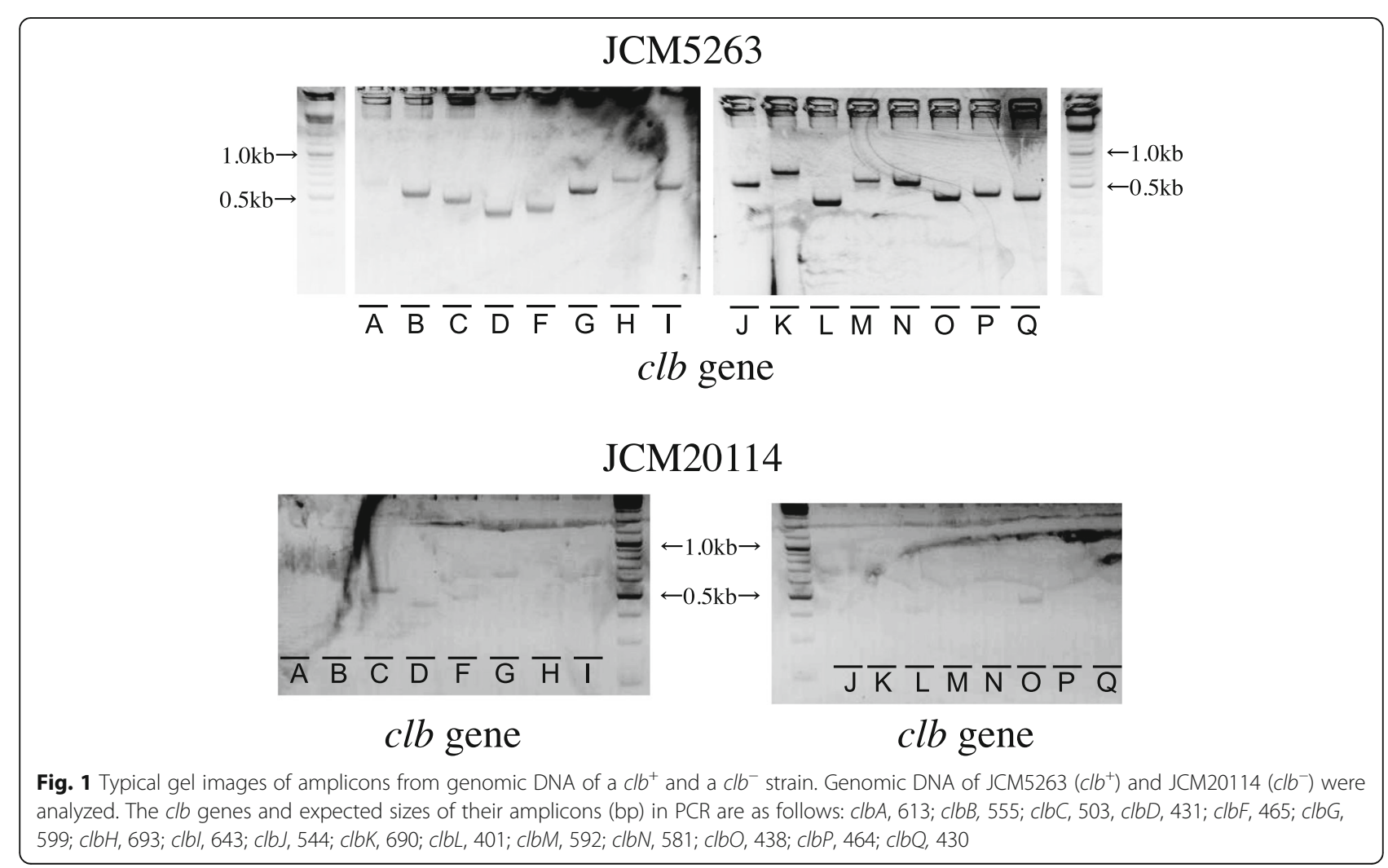



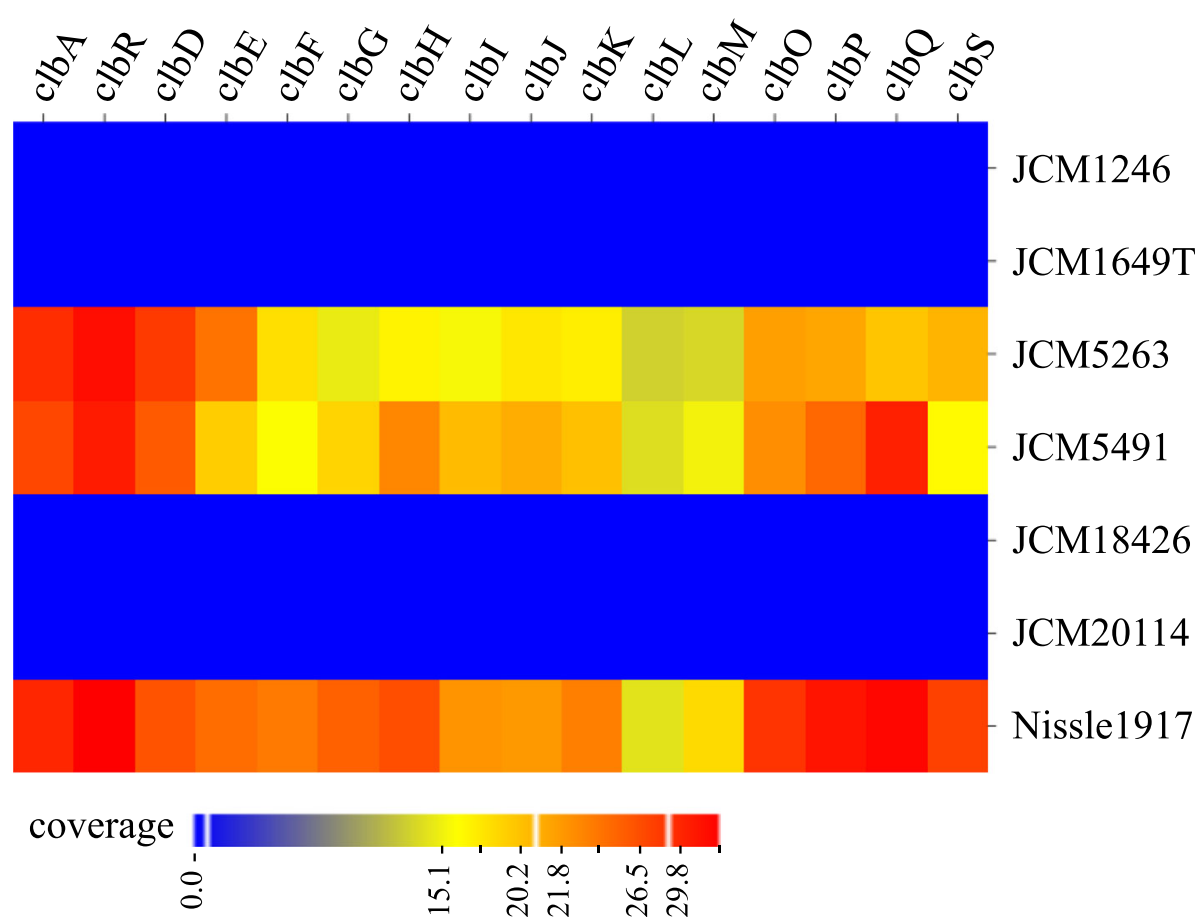

Fig. 2 The read coverage of the clb genes in genomic DNA of E. coli strains determined by Illumina MiSeq. The color represents the read coverage of the indicated $\mathrm{clb}$ gene in the indicated strains

\section{Infection and in vitro micronucleus test}

Bacterial infection to Chinese hamster ovary $(\mathrm{CHO})$ AA8 cells and the MN test were carried out as previously described [5]. Briefly, the CHO cells $\left(4 \times 10^{5}\right.$ cells/ dish) were seeded in $\$ 60 \mathrm{~mm}$ plastic cell culture dishes 1 day before the infection procedure. The bacteria were cultured until $\mathrm{OD}_{595}=0.5$ at $37^{\circ} \mathrm{C}$ in Infection Medium (IM) (RPMI1640 medium (Nacalai Tesque., Kyoto, Japan) + $25 \mathrm{mM}$ HEPES, $5 \%$ fetal bovine serum (FBS, Sigma-Aldrich, MO USA)). The infection was carried out with $3 \mathrm{~mL}$ of IM containing $E$. coli at the indicated multiplicity of infection (MOI) (number of bacteria per cell at the onset of infection). After being treated with bacteria for $4 \mathrm{~h}$, the $\mathrm{CHO}$ cells were cultured for a further $20 \mathrm{~h}$ in cell culture medium supplemented with $200 \mu \mathrm{g} / \mathrm{mL}$ gentamicin (Nacalai Tesque). The MN test was then performed, and the number of cells with $\mathrm{MN}$ was recorded based on the observation of 1000 interphase cells. Relative cell growth was calculated using the formula:

$$
\begin{aligned}
\text { Relative cell growth } & =(\text { number of treated cells }) \\
& \div(\text { number of non-treated cells })
\end{aligned}
$$

\section{umu test}

The DNA damaging potency of bacterial cell extracts was estimated using the umu test, as previously described [5]. Briefly, E. coli cells were harvested from $10 \mathrm{~mL}$ of overnight culture in LB media (O.D. $=1.7-2$ ) by centrifugation, and extracts of $E$. coli were prepared with $1 \mathrm{~mL}$ of BugBuster protein extraction reagent (Novagen, Merck Millipore Co., Tokyo, Japan). The cell lysates were collected by centrifugation at $16,000 \times \mathrm{g}$ for $20 \mathrm{~min}$ at $4{ }^{\circ} \mathrm{C}$. The $u m u$ assay using ZA227/pSK1002 tester strain was conducted as previously reported $[6,7]$. ZA227 is derived from E. coli $\mathrm{K}-12$, which dose not posses the $c l b$ gene cluster [1]. The tester strain in $1 \mathrm{~mL}$ of the TGA medium and $20 \mu \mathrm{L}$ of the extracts from the $c l b^{+}$E. coli strains were incubated for $3 \mathrm{~h}$ at $37^{\circ} \mathrm{C}$. As a solvent and positive controls, $20 \mu \mathrm{L}$ of BugBuster solution and $10 \mu \mathrm{L}$ of $1 \mu \mathrm{g} / \mathrm{mL}$ 4-nitroquinoline 1-oxide (4NQO) (Nacalai Tesque) were used, respectively.

\section{Results and discussion \\ Genotyping}

First, we assessed the presence of the $c l b$ genes, i.e., 16 $c l b$ genes (clbA-clbD, $c l b F-c l b Q)$ by detecting each amplicon after PCR with specific primer sets to the genes. As a positive control strain, we analyzed the known $\mathrm{clb}^{+}$strain Nissle 1917, which is a commensal strain also widely used as a probiotic treatment for intestinal disorders [1]. In genomic DNA from JCM5263, JCM5491 and Nissle 1917, we observed amplicons corresponding to all $16 \mathrm{clb}$ genes (Table 1 and Fig. 1). However, some or all of the amplicons corresponding to the 

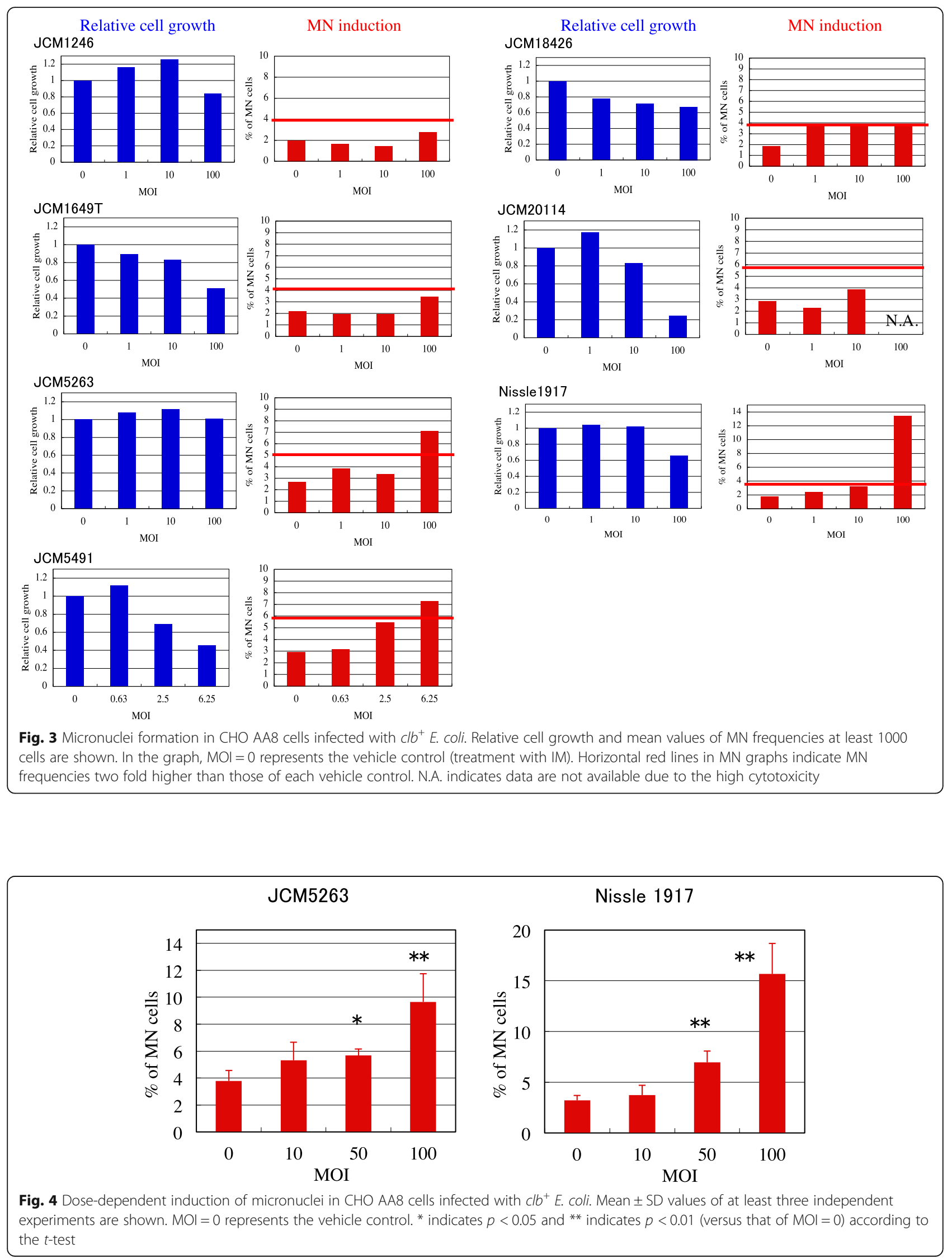


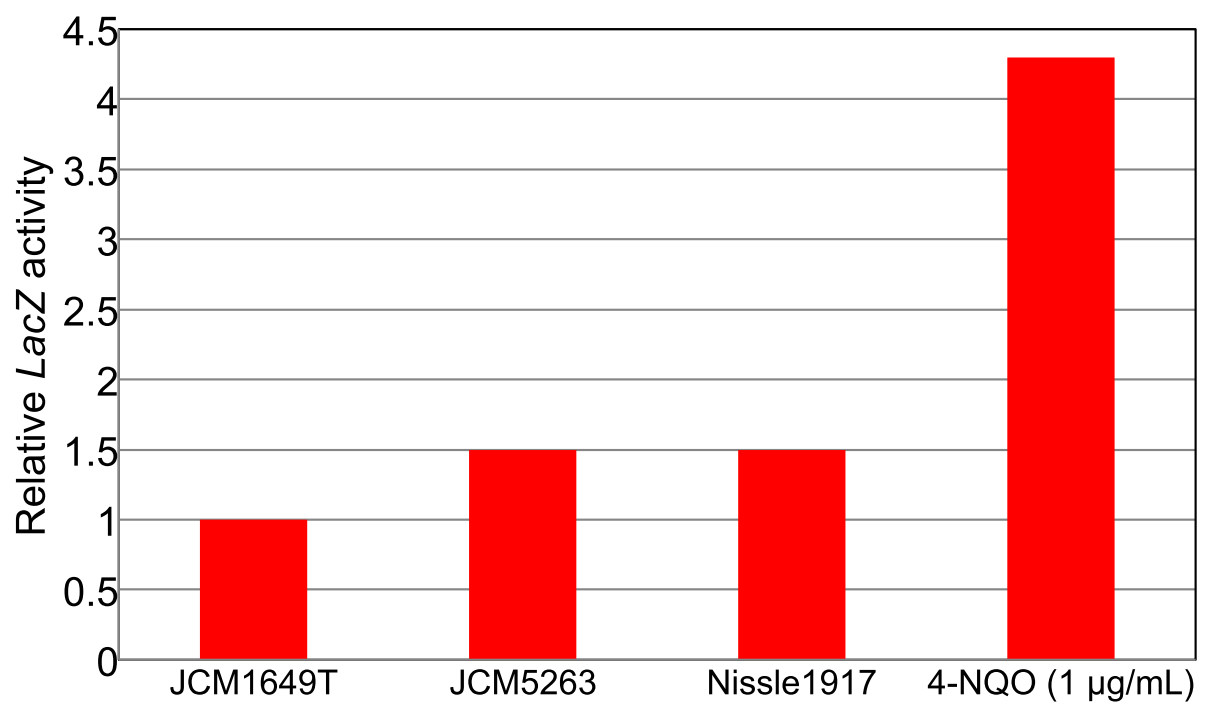

Fig. 5 Induction of SOS response (umuC gene) by E. coli extracts in umu test. Relative LacZ activity to the $\mathrm{Clb}^{-}$strain JCM1649T. Mean values of duplicated determinations are shown. 4-NQO as a positive control of DNA damaging agent (incubated for $3 \mathrm{~h}$ at $37^{\circ} \mathrm{C}$ )

16 genes were not detected in JCM1649T, JCM1246, JCM18426 and JCM20114. The presence or absence of the $c l b$ gene cluster in the strains was also confirmed with next-generation sequencing of the bacterial genomic DNA (Fig. 2). We concluded that three among seven strains, i.e., six strains randomly chosen from the Japan Collection of Microorganisms and the positive control strain Nissle 1917, harbored the $\mathrm{clb}$ gene cluster (Table 1). It has been reported that $20.8 \%$ of healthy people who have neither inflammatory bowel disease nor colorectal cancer as well as $66.7 \%$ of colorectal cancer patients harbor $\mathrm{clb}^{+}$E. coli [8]. Furthermore, this gene cluster is found not only in E. coli but also in Klebsiella pneumoniae, Enterobacter aerogenes and Citrobacter koseri $[8,9]$. The bacterial $c l b$ gene cluster seems to be well-distributed in nature.

\section{In vitro genotoxicity analysis}

Next, for screening of their genotoxicities, the MNinducing activity of the E. coli strains was examined using the $\mathrm{CHO}$ AA8 cell line, since the test is a convenient and reliable for evaluating genotoxicity [10]. As shown in Fig. 3, the degree of induction varied among the strains. In the present study, we determined that $E$. coli induces $\mathrm{MN}$-frequency at least twofold compared with $\mathrm{MOI}=0$ as an MN-induction positive strain. Evidently, JCM5263 and Nissle 1917 were $\mathrm{MN}$-induction positive strains, that is, infection of both strains at MOI $=100$ induced $\mathrm{MN}$ with frequency 2.5- to 7-fold greater than that at $\mathrm{MOI}=0$. The level of cytotoxicity also varied. Infection of JCM5491 and JCM20114 led to high cytotoxic effects in $\mathrm{CHO}$ cells. The relative growths of $\mathrm{CHO}$ cells treated with JCM5491 and JCM20114 at MOI $=100$ were $2.6 \%$ (data not shown) and $24 \%$, respectively. JCM5491 and JCM20114 were hemolysin-positive strains (data not shown), therefore, their high cytotoxicity might be involved in hemolysin. Since the $\mathrm{MN}$ test cannot be performed under such highlycytotoxic conditions, we tried lower-MOI treatments and found that at MOI $=6.25$, JCM5491 induced MN with frequency 2.5 -fold greater than that at $\mathrm{MOI}=0$ (Fig. 3). We concluded that $\mathrm{clb}^{+}$JCM5263, JCM5491 and Nissle 1917 are $\mathrm{MN}$-induction positive strains (Table 1). We also confirmed that infections with JCM5263 and Nissle 1917 resulted in dosedependent MN-inductions (Fig. 4).

Since DNA damage is known to induce MN [10], we examined the extracts of $\mathrm{clb}^{+}$E. coli (JCM5263 and Nissle 1917) for induction of an SOS response in the umu test. The extracts were prepared using BugBuster reagent, which disrupts the cell walls and liberates the cytosol. Increased SOS responses were observed in the extracts of $\mathrm{clb}^{+}$from both JCM5263 and Nissle 1917 compared with that of $\mathrm{clb}^{-}$ JCM1649T (Fig. 5). The relative SOS-induction levels by the extracts of both JCM5263 and Nissle 1917 were 1.5 times higher than that of JCM1649T. The induction level by the positive control agent 4-NQO $(1.0 \mu \mathrm{g} / \mathrm{mL})$ was 4.3 -fold that by JCM1649T. These results indicate that the $c l b^{+} E$. coli extracts have weak potency for SOS induction. The clbS gene encodes a resistance protein blocking the genotoxicity of colibactin and ClbS protein functions as an antidote for colibactin-autotoxicity in $\mathrm{clb}^{+}$E. coli [11]. Presumably, the presence of $\mathrm{ClbS}$ protein in the extracts in the 
present study attenuated their DNA-damaging potency.

\section{Conclusion}

Genotyping analysis revealed that two of six E. coli strains randomly chosen from the Japan Collection of Microorganisms possessed a $\mathrm{clb}$ gene cluster. The $\mathrm{clb}^{+}$ JCM5263, JCM5491 and Nissle 1917 (as $c l b^{+}$control strain) exhibited $\mathrm{MN}$ induction in $\mathrm{CHO}$ cells. The cell extracts of JCM5263 and Nissle 1917 also had DNAdamaging potency in a bacterial $u m u$ test. These results support the observations that $c l b$ gene clusters are widely distributed in nature and that $c l b^{+} E$. coli, which has genotoxic potency, is not rare among microorganisms.

\section{Abbreviations}

4-NQO: 4-nitroquinoline 1-oxide; $\mathrm{CHO}$ : Chinese hamster ovary;

$\mathrm{Clb}^{+}$: colibactin-producing; MN: micronucleus; MOl: multiplicity of infection

\section{Acknowledgements}

Not applicable.

\section{Authors' contribution}

MK, K. Wakabayashi and K. Watanabe designed the study. MK, Y Hisatomi and CS performed micronucleus assays with mammalian cells. YO carried out umu tests. YT, MS, Y Hirayama, NM and YY conducted genotyping. HS, $\mathrm{YI}, \mathrm{MM}, \mathrm{HI}$ and TY critically discussed the study. MK wrote the manuscript. All authors read and approved the final manuscript.

\section{Authors' information}

Not applicable.

\section{Funding}

This study was supported by Grants-in-Aid for Scientific Research (Grant Number: 17 K08841) from the Japan Society for the Promotion of Science (JSPS) to Y.Y. and the Development of Innovative Research on Cancer Therapeutics from Japan Agency for Medical Research and Development (AMED) (K. Watanabe, 16ck0106243h0001), Innovative Areas from MEXT, Japan (K. Watanabe, 16H06449), the Takeda Science Foundation (K. Watanabe), the Institution of Fermentation at Osaka (K. Watanabe), the Princess Takamatsu Cancer Research Fund (K. Watanabe, 16-24825), and the Yakult Bio-Science Foundation (K. Watanabe).

Availability of data and materials

Not applicable.

Ethics approval and consent to participate

Not applicable.

Consent for publication

Not applicable.

\section{Competing interests}

The authors declare that they have no competing interests.

\section{Author details}

${ }^{1}$ Graduate School of Science and Radiation Research Center, Osaka Prefecture University, 1-2 Gakuen-cho, Naka-ku, Sakai-shi, Osaka 599-8570, Japan. ${ }^{2}$ Department of Pharmaceutical Sciences, University of Shizuoka, Shizuoka, Japan. ${ }^{3}$ Graduate Division of Nutritional and Environmental Sciences, University of Shizuoka, Shizuoka, Japan. ${ }^{4}$ Department of Tumor Pathology, Hamamatsu University School of Medicine, Shizuoka, Japan. ${ }^{5}$ School of Veterinary Medicine, Faculty of Veterinary Science, Nippon Veterinary and Life Science University, Tokyo, Japan. 'Division of Prevention, Center for Public Health Sciences, National Cancer Center, Tokyo, Japan.
${ }^{7}$ Department of Molecular-Targeting Cancer Prevention, Kyoto Prefectural University of Medicine, Kyoto, Japan.

Received: 24 January 2020 Accepted: 17 February 2020

Published online: 11 March 2020

\section{References}

1. Nougayrede JP, Homburg S, Taieb F, Boury M, Brzuszkiewicz E, Gottschalk G, Buchrieser C, Hacker J, Dobrindt U, Oswald E. Escherichia coli induces DNA double-strand breaks in eukaryotic cells. Science. 2006;313:848-51.

2. Cuevas-Ramos G, Petit CR, Marcq I, Boury M, Oswald E, Nougayrede JP. Escherichia coli induces DNA damage in vivo and triggers genomic instability in mammalian cells. Proc Natl Acad Sci U S A. 2010;107:11537-42.

3. Vizcaino MI, Crawford JM. The colibactin warhead crosslinks DNA. Nat Chem. 2015;7:411-7.

4. Hirayama Y, Tsunematsu Y, Yoshikawa Y, Tamafune R, Matsuzaki N, Iwashita Y, Ohnishi I, Tanioka F, Sato M, Miyoshi N, Mutoh M, Ishikawa H, Sugimura H, Wakabayashi K, Watanabe K. Activity-based probe for screening of highcolibactin producers from clinical samples. Org Lett. 2019;21:4490-4.

5. Kawanishi M, Hisatomi Y, Oda Y, Shimohara C, Tsunematsu Y, Sato M, Hirayama $Y$, Miyoshi N, Iwashita $Y$, Yoshikawa $Y$, Yagi T, Sugimura $H$, Wakabayashi K, Watanabe K. In vitro genotoxicity analyses of E. coli producing colibactin isolated from a Japanese colorectal cancer patient. J Toxicol Sci. 2019:44(12):871-6.

6. Oda Y. Development and progress for three decades in umu test systems. Genes Environ. 2016;38:24.

7. Oda Y, Nakamura S, Oki I, Kato T, Shinagawa H. Evaluation of the new system (umu-test) for the detection of environmental mutagens and carcinogens. Mutat Res. 1985;147:219-29.

8. Arthur JC, Perez-Chanona E, Muhlbauer M, Tomkovich S, Uronis JM, Fan TJ, Campbell BJ, Abujamel T, Dogan B, Rogers AB, Rhodes JM, Stintzi A, Simpson KW, Hansen JJ, Keku TO, Fodor AA, Jobin C. Intestinal inflammation targets cancer-inducing activity of the microbiota. Science. 2012;338:120-3.

9. Putze J, Hennequin C, Nougayrede JP, Zhang W, Homburg S, Karch H, Bringer MA, Fayolle C, Carniel E, Rabsch W, Oelschlaeger TA, Oswald E, Forestier C, Hacker J, Dobrindt U. Genetic structure and distribution of the colibactin genomic island among members of the family Enterobacteriaceae. Infect Immun. 2009;77:4696-703.

10. Hayashi M. The micronucleus test -most widely used in vivo genotoxicity test. Genes Environ. 2016;38:18.

11. Bossuet-Greif N, Dubois D, Petit C, Tronnet S, Martin P, Bonnet R, Oswald E, Nougayrede JP. Escherichia coli ClbS is a colibactin resistance protein. Mol Microbiol. 2016;99:897-908.

\section{Publisher's Note}

Springer Nature remains neutral with regard to jurisdictional claims in published maps and institutional affiliations.

\section{Ready to submit your research? Choose BMC and benefit from:}

- fast, convenient online submission

- thorough peer review by experienced researchers in your field

- rapid publication on acceptance

- support for research data, including large and complex data types

- gold Open Access which fosters wider collaboration and increased citations

- maximum visibility for your research: over $100 \mathrm{M}$ website views per year

At BMC, research is always in progress.

Learn more biomedcentral.com/submissions 